\title{
Evaluation of Binding Selectivity of a Polyamide Probe to Single Base-Pair Different DNA in A.T-Rich Region by Electrospray Ionization Mass Spectrometry
}

\author{
Huihui Li and Gu Yuan \\ Beijing National Laboratory for Molecular Sciences, Key Laboratory of Bioorganic Chemistry and Molecular \\ Engineering of Ministry of Education, Department of Chemical Biology, College of Chemistry and Molecular \\ Engineering, Peking University, Beijing, China
}

In this study, electrospray ionization mass spectrometry (ESI-MS) was used for the evaluation of the binding selectivity of a polyamide probe to single-base pair different DNA in an A.T-rich region. In this procedure, $\Delta \operatorname{Ir}\left(\mathrm{ds}_{n}\right)$ was introduced as a parameter to compare the binding affinities of the polyamides with the duplex DNA. The results show that ESI-MS is a very useful tool for analysis of binding selectivity of a polyamide probe to single-base pair different DNA. (J Am Soc Mass Spectrom 2006, 17, 1742-1748) (C) 2006 American Society for Mass Spectrometry

S ingle base pair different (SBPD) DNA is a very important phenomenon in biological systems. The difference of a single-base pair at some promoters could cause differential activation of transcription [1] and expression [2]. The discrimination of SBPD in DNA sequences allows exploration of biological phenomena [3].

Polyamides containing $N$-methylpyrrole have attracted considerable attention in the fields of chemical biology and medicine because they can permeate cell membranes, then recognize and bind with a high affinity in the minor groove of predetermined DNA sequences [4-14].

There are several solution phase methods for determining binding affinities and sequence selectivities; for example, quantitative DNase I footprint titrations, NMR studies, and spectrophotometry [15-18]. DNase I footprint titrations have been used in recent years to determine binding affinities and calculate the equilibrium association constant $K_{\mathrm{a}}$, especially for studies of specificity toward mismatches $[15,16]$. However, this method is labor-intensive in the preparation of ${ }^{32} \mathrm{P}$ labeled, PCR-amplified DNA fragments and for the titrations, and may require large quantities of material.

Electrospray ionization mass spectrometry (ESI-MS) is a rapid method with a high level of sensitivity for the analysis of noncovalent complexes between drugs and

Published online September 11, 2006

Address reprint requests to Dr. G. Yuan, Beijing National Laboratory for Molecular Sciences, Key Laboratory of Bioorganic Chemistry and Molecular Engineering of Ministry of Education, Department of Chemical Biology, College of Chemistry and Molecular Engineering, Peking University, Beijing 100871, China. E-mail: guyuan@pku.edu.cn
DNA. ESI-MS also gives direct information about the stoichiometry of the complexes [19-26].

In this study, the ATATAA element in the HIV-1 promoter, which is a natural binding site for the TATA box-binding protein (TBP) and plays a key role in the activation of the transcription of HIV-1 [27-30], was selected as the target, and a novel polyamide probe, PyPyPyPy $\beta$ Dp, was designed and synthesized according to the pairing rules derived by Dervan [31] for the recognition of the ATATAA element. The goal of this research is to develop an ESI-MS method for evaluating the binding selectivity of PyPyPyPy $\beta$ D p to SBPD DNA. The results show that ESI-MS is a very useful tool for the analysis of the binding selectivity of the polyamide probe to SBPD DNA.

\section{Experimental}

DNA

Single-stranded oligonucleotides were purchased from AuGCT (Beijing, China). Oligodeoxynucleotides were dissolved in deionized water and diluted with $500 \mathrm{mM}$ ammonium acetate. For duplex DNA (Table 1), two complementary single-stranded oligonucleotides were mixed in equimolar proportions, annealed at $90{ }^{\circ} \mathrm{C}$ and cooled slowly to room temperature (over $4 \mathrm{~h}$ ) to allow the formation of the duplex $\left(\mathbf{d s}_{n}, n=1-7,11-16\right)$.

\section{Probe}

A polyamide, PyPyPyy $\beta$ D, was designed and synthesized in our laboratory $[32,33]$. 
Table 1. The sequences and monoisotopic masses of the target duplex DNA $\left(\mathrm{ds}_{n}\right)$

\begin{tabular}{llc}
\hline Oligonucleotide $\left(\mathrm{ds}_{n}\right)$ & \multicolumn{1}{c}{ Sequence } & Monoisotopic mass (Da) \\
\hline \hline $\mathrm{ds}_{1}$ & $\mathrm{~d}($ CTGCATATAAGCAG/CTGCTTATATGCAG) & 8525.8 \\
$\mathrm{ds}_{2}$ & $\mathrm{~d}($ CTGCGGATAAGCAG/CTGCTTATCCGCAG) & 8527.8 \\
$\mathrm{ds}_{3}$ & $\mathrm{~d}($ CTGCATATGGGCAG/CTGCCCATATGCAG) & 8527.8 \\
$\mathrm{ds}_{4}$ & $\mathrm{~d}($ CTGCGGGTAAGCAG/CTGCTTACCCGCAG) & 8528.8 \\
$\mathrm{ds}_{5}$ & $\mathrm{~d}($ CTGCATAGGGGCAG/CTGCCCCTATGCAG) & 8528.8 \\
$\mathrm{ds}_{6}$ & $\mathrm{~d}($ CTGCAGCGCAGCAG/CTGCTGCGCTGCAG) & 8529.8 \\
$\mathrm{ds}_{7}$ & $\mathrm{~d}($ CTGCCGCGCGGCAG) & 8531.8 \\
$\mathrm{ds}_{11}$ & $\mathrm{~d}($ CTGCGTATAAGCAG/CTGCTTATACGCAG) & 8526.8 \\
$\mathrm{ds}_{12}$ & $\mathrm{~d}($ CTGCAGATAAGCAG/CTGCTTATCTGCAG) & 8526.8 \\
$\mathrm{ds}_{13}$ & $\mathrm{~d}($ CTGCATGTAAGCAG/CTGCTTACATGCAG) & 8526.8 \\
$\mathrm{ds}_{14}$ & $\mathrm{~d}($ CTGCATAGAAGCAG/CTGCTTCTATGCAG) & 8526.8 \\
$\mathrm{ds}_{15}$ & $\mathrm{~d}$ (CTGCATATGAGCAG/CTGCTCATATGCAG) & 8526.8 \\
$\mathrm{ds}_{16}$ & $\mathrm{~d}($ CTGCATATAGGCAG/CTGCCTATATGCAG) & 8526.8 \\
\hline
\end{tabular}

\section{Sample Preparation for Noncovalent Interaction Assays}

Desalting was performed three times with Microcon filters (Amicon, Beverly, MA) with a 3000 Da cut-off. The resulting DNA stock solution was $500 \mu \mathrm{M}$ in 100-150 $\mathrm{mM} \mathrm{NH}_{4} \mathrm{OAc}$.

The polyamide was dissolved at a concentration of $500 \mu \mathrm{M}$ in methanol/water (50:50, vol/vol). Each $2.0 \mu \mathrm{L}$ DNA sample was mixed with $2.0-12 \mu \mathrm{L}$ of a polyamide solution, and then diluted with methanol/100 mM ammonium acetate $(20: 80, \mathrm{vol} / \mathrm{vol})$ to $40 \mu \mathrm{L}$. Methanol was used to obtain a good spray [20, 21]. To avoid formation of nonspecific dimers between identical single-stranded oligonucleotides, a final concentration of the oligonucleotide as low as $2.5 \times 10^{-5} \mathrm{M}$ was required in each solution.

\section{Mass Spectrometry}

ESI mass spectra were obtained with a Finnigan LCQ Deca XP Plus ion trap mass spectrometer (Thermo Finnigan, San Jose, CA), and all the experiments were carried out in the negative ion mode. We infused the complex solution directly into the mass spectrometer at a flow-rate of $2 \mu \mathrm{L} / \mathrm{min}$. The electrospray source conditions were optimized to favor the observation of the noncovalent complexes; in our case, spray voltage was $2.0 \mathrm{kV}$ and capillary temperature was $120^{\circ} \mathrm{C}$. Data were collected and analyzed with the Xcalibur software developed by Thermo Finnigan, and 10 scans were averaged for each spectrum.

\section{Analysis of Binding Affinity for a Polyamide Probe with Duplex DNA}

Using the ESI-MS approach, the stoichiometry and relative abundance of both free DNA and the DNApolyamide complex can be determined simultaneously. Under the solution conditions used, almost all of the DNA signals come from the 5-charge state, and the complex of polyamide (P) with the DNA does not change the observed charge state.
Here, $\Delta \mathrm{I}_{\mathrm{r}}\left(\mathrm{ds}_{n}\right)$ was introduced as a parameter to compare binding affinities of the polyamide to the duplex DNA.

First, the abundance ratio of the complex ion to the duplex ion, $\mathrm{I}_{\mathrm{r}}\left(\mathrm{ds}_{n}\right)$, was calculated:

$$
\mathrm{I}_{\mathrm{r}}\left(\mathrm{ds}_{\mathrm{n}}\right)=\frac{\mathrm{I}\left(\mathrm{ds}_{\mathrm{n}}+2 \mathrm{P}\right)}{\mathrm{I}\left(\mathrm{ds}_{\mathrm{n}}\right)}
$$

where $\mathrm{I}\left(\mathrm{ds}_{n}\right)$ and $\mathrm{I}\left(\mathrm{ds}_{n}+2 \mathrm{P}\right)$ are the relative abundances of $\left[\mathrm{ds}_{n}\right]^{5-}$ and $\left[\mathrm{ds}_{n}+2 \mathrm{P}\right]^{5-}$, respectively. The percentage for each sample in each trial was calculated, using that of $\mathbf{d s}_{\mathbf{1}}$ as a reference:

$$
\Delta \mathrm{I}_{\mathrm{r}}\left(\mathrm{ds}_{\mathrm{n}}\right)=\frac{\mathrm{I}_{\mathrm{r}}\left(\mathrm{ds}_{\mathrm{n}}\right)}{\mathrm{I}_{\mathrm{r}}\left(\mathrm{ds}_{\mathrm{I}}\right)} \times 100 \%
$$

Thus, the relative ratio $\Delta \mathrm{I}_{\mathrm{r}}\left(\mathrm{ds}_{n}\right)$ could be obtained for the relative binding affinities of the polyamide to these different DNAs.

\section{Fluorescence Titration}

The fluorescence was measured with a Hitachi F-4500 spectrofluorimeter (Tokyo, Japan). First, a 1-mL quartz cuvette was loaded with Tris buffer $(0.5 \mathrm{~mL}, 0.1 \mathrm{M}$ $\mathrm{NaCl}, 0.1 \mathrm{M}$ Tris, $\mathrm{pH}$ 8.0) and ethidium bromide $(7 \mu \mathrm{M}$ final concentration). Then the oligonucleotide $\mathrm{ds}_{n}$ was added (1 $\mu \mathrm{M}$ final concentration). Titrations were conducted by adding aliquots of polyamide $(1 \mu \mathrm{L}, 0.1 \mathrm{mM})$ and measuring the resultant decrease of fluorescence after $5 \mathrm{~min}$ equilibration. Additions were continued until the system reached saturation.

\section{Results and Discussion}

Binding of Polyamide to $d s_{1}$

The ESI mass spectrum of duplex DNA d(CTGCATATAAGCAG/CTGCTTATATGCAG) shows that the duplex ion $\left(\left[\mathrm{ds}_{1}\right]^{5-}\right)$ at $m / z 1704$ is a base peak $(100 \%)$, which is a target ion for the polyamide (P) recognizing molecule (Scheme 1). The complexes 


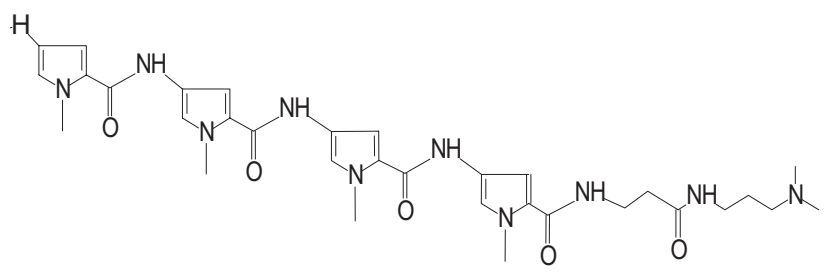

Scheme 1. Structure of PyPyPyPy $\beta \mathrm{Dp}(\mathbf{P})$.

were analyzed by ESI-MS of mixtures of the duplex DNA with $\mathbf{P}$ in different molar ratios, ranging from 1:1 to 1:6. The great advantage of mass spectrometry over other methods is that all species of different masses can be clearly distinguished. Generally, in each spectrum, there were three kinds of ions: the free duplex oligonucleotide ion (ds), the 1:1 and 1:2 complex ions of duplex DNA, and polyamide (ds $+n \mathbf{P}, n$ $=1$ or 2 ). Stepwise addition of $\mathbf{P}$ to a $25 \mu \mathrm{M}$ DNA solution resulted in a gradual increase of the relative abundance of the ion corresponding to $\left[\mathrm{ds}_{1}+2 \mathrm{P}\right]^{5-}$ at $\mathrm{m} / \mathrm{z}$ 1963. Figure 1 shows an ESI mass spectrum in which the polyamide as the probe binds the target DNA $\left(\mathrm{ds}_{1}\right)$ from the HIV-1 promoter. When the molar ratio of the DNA to $\mathbf{P}$ is 1:4, the ions of the duplex and the 1:1 complex ion, $\left[\mathrm{ds}_{1}\right]^{5-}$ and $\left[\mathrm{ds}_{1}+\mathrm{P}\right]^{5-}(\mathrm{m} / z 1704$ and 1833, respectively), had only poor abundance (no more than $10 \%$ ), while the $1: 2$ complex ion ([ $\mathrm{ds}_{1}+$ $2 \mathrm{P}]^{5-}$ at $m / z 1963$ ) became significant, with the greatest abundance $(100 \%)$. This result demonstrates that, compared with the 1:1 complex, a significant amount of the complex with a 1:2 $\left(\mathbf{d s}_{\mathbf{1}}+2 \mathbf{P}\right)$ ratio existed in the solution as the mixing molar ratio was raised to 1:4. When the molar ratio of DNA to $\mathbf{P}$ was increased to $1: 6$, the ions of the duplex and the 1:1 complex, $\left[\mathrm{ds}_{1}\right]^{5-}$ and $\left[\mathrm{ds}_{1}+\mathrm{P}\right]^{5-}$, almost could not be observed, while the 1:2 complex ion $\left(\left[\mathrm{ds}_{1}+2 \mathrm{P}\right]^{5-}\right)$ maintained the greatest abundance. These results

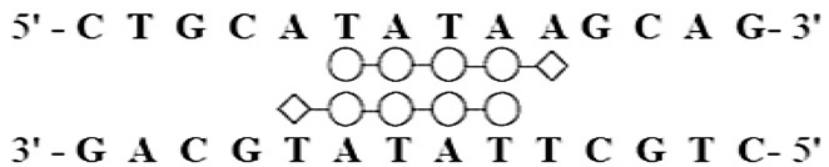

Scheme 2. The 2:1 binding motif for РyРyРyРy $\beta$ Dp and $\mathbf{d s}_{\mathbf{1}}$. Open circles represent pyrrole. Open diamonds represent $\beta$ alanine $(\beta)$ and dimethylaminopropylamide $(\mathrm{Dp})$.

indicated that the binding stoichiometry of $1: 2\left(\left[\mathrm{ds}_{1}+\right.\right.$ $2 \mathrm{P}]^{5-}$ at $\mathrm{m} / \mathrm{z}$ 1963) was dominant for complexes observed under these conditions.

According to the ESI mass spectra of the mixtures of $\mathrm{ds}_{1}$ with $\mathbf{P}$ and the rules for DNA recognition [31], in which Py/Py targets A.T or T.A, P (PyPyPyPy $\beta$ Dp) in a 2:1 model binds to the ATATAA sequence in the minor groove of $\mathrm{ds}_{\mathbf{1}}$ (Scheme 2 ).

\section{Binding Selectivity of P with Two to Six Base Pairs Different DNA}

To evaluate the binding characteristic of $\mathbf{P}$ to the ATATAA sequence of the target DNA, we examined six variants of DNA, ds $\mathbf{s}_{2}$ to $\mathrm{ds}_{7}$, of which 2 to $6 \mathrm{~A} \cdot \mathrm{T}$ base pairs were changed to G.C in the ATATAA element (Table 1). To better understand the interaction of $\mathbf{P}$ with DNA, the abundance ratio of the complex ion to the duplex ion and the relative binding affinities are calculated in the forms of $\mathrm{I}_{\mathrm{r}}\left(\mathrm{ds}_{n}\right)$ and $\Delta \mathrm{I}_{\mathrm{r}}\left(\mathrm{ds}_{n}\right)$ by eqs 1 and 2.

The ESI mass spectra of the noncovalent interaction were analyzed by mixing $\mathbf{d s}_{2}$ to $\mathbf{d s}_{\mathbf{7}}$ DNA with $\mathbf{P}$ in different molar ratios, ranging from 1:1 to 1:6; Figure 2 shows the ESI mass spectra of $\mathbf{d s}_{2}$ as examples. Generally, in each spectrum, the type of ion is similar to that of $\mathbf{d s}_{\mathbf{1}}$ at each titration point: i.e., the duplex ions $\left(\mathbf{d s}_{n}\right)$ and the complex ions of duplex DNA and the polyamide $\left(\mathrm{ds}_{n}+\mathrm{P}\right.$ and $\left.\mathrm{ds}_{n}+2 \mathrm{P}\right)$ with

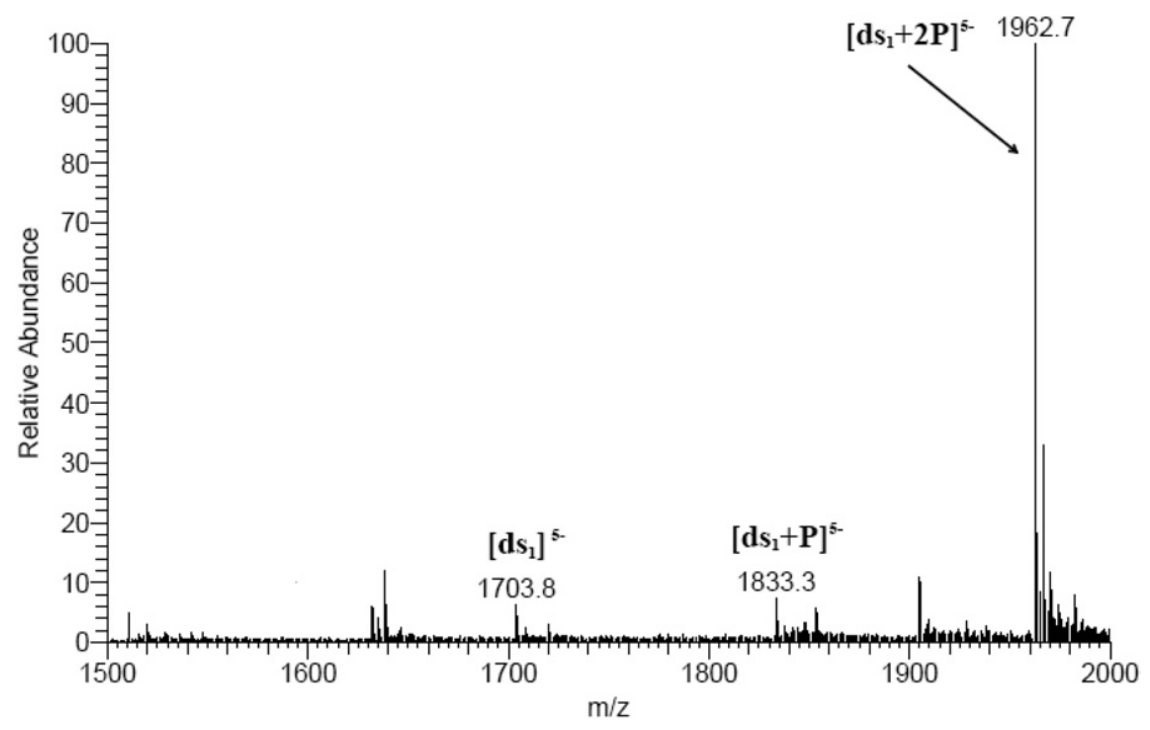

Figure 1. Negative ion ESI mass spectrum of the mixture of $\mathbf{d s}_{\mathbf{1}}$ with $\mathbf{P}$ in a 1:4 $\mathbf{M}$ ratio. 

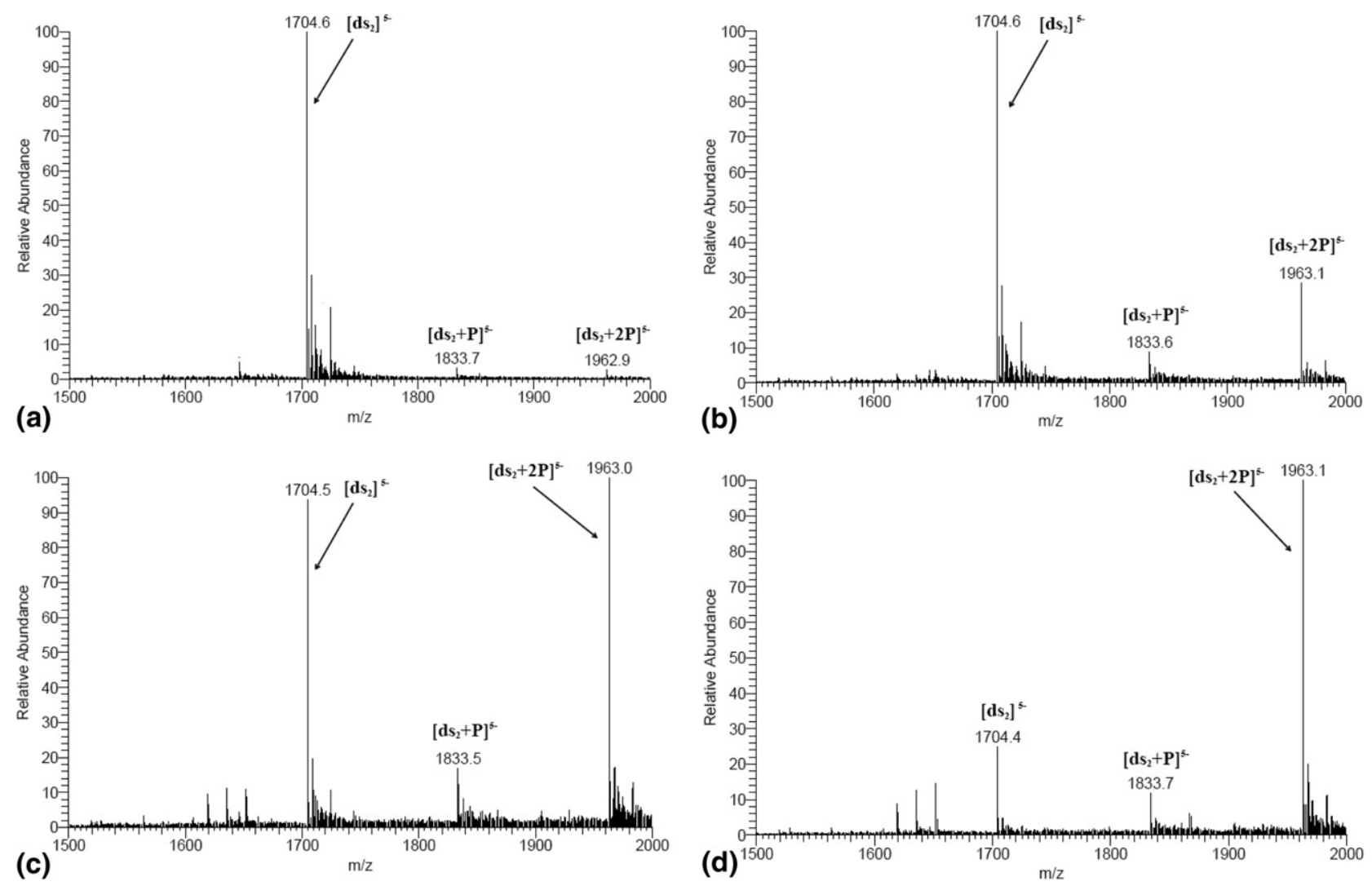

Figure 2. Negative ion ESI mass spectra of the mixtures of $\mathbf{d s}_{2}$ with $\mathbf{P}$ in the molar ratio of (a) $1: 1 ;(\mathbf{b})$ $1: 2 ;$ (c) $1: 4 ;$ (d) $1: 6$

the charge state of 5-. The stepwise addition of $\mathbf{P}$ to the DNA solution resulted in a gradual increase of the relative abundance of the ion corresponding to $\left[\mathrm{ds}_{2}+2 \mathrm{P}\right]^{5-}$ at $m / z 1963$, which became significant with the greatest abundance at the $1: 4 \mathrm{M}$ ratio. The relative abundance of $\left[\mathrm{ds}_{2}+\mathrm{P}\right]^{5-}$ complex ion at $\mathrm{m} / \mathrm{z}$ 1833 increased to no more than $20 \%$ as the molar ratio increased from $1: 1$ to $1: 4$, and then decreased when the molar ratio was increased to 1:6.

The negative-ion ESI mass spectrum of the mixture of $\mathbf{d s}_{3}$ with $\mathbf{P}$ in a 1:4 $\mathrm{M}$ ratio contains three main monoisotopic peaks of $m / z 1704.5\left(\left[\mathrm{ds}_{3}\right]^{5-}\right), 1833.5\left(\left[\mathrm{ds}_{3}+\mathrm{P}\right]^{5-}\right)$, and $1963.0\left(\left[\mathrm{ds}_{3}+2 \mathrm{P}\right]^{5-}\right)$ and their relative intensities are 100,10 , and $58 \%$, respectively. In the case of $\mathbf{d s}_{5}$, three main peaks are $\mathrm{m} / \mathrm{z} 1704.8(82 \%), 1833.9(22 \%), 1963.4$ $(100 \%)$, and $\mathrm{m} / \mathrm{z} 1705.4(100 \%), 1834.6(19 \%), 1963.9(7 \%)$ for $\mathbf{d s}_{7}$. The ESI mass spectra of mixtures of $\mathbf{d s}_{2}$ to $\mathrm{ds}_{5}$ with $\mathbf{P}$ in the molar ratio of 1:4 showed the higher $\left[\mathrm{ds}_{n}+2 \mathrm{P}\right]^{5-}$ peak. However, the relative abundance of $\left[\mathrm{ds}_{n}+2 \mathrm{P}\right]^{5-}$ in $\mathbf{d s}_{\mathbf{6}}$ and $\mathbf{d s}_{7}$ is much lower than that between $\mathbf{P}$ and other target DNA; it shows very low binding affinities because there are no continuous A.T base pairs.

The ESI MS results show the effects of the molar ratio of the duplex to $\mathbf{P}(1: 1-1: 6)$ on the abundance ratio of $\left[\mathrm{ds}_{1}+\right.$ $2 \mathrm{P}]^{5-}$ to $\left[\mathrm{ds}_{1}\right]^{5-}$, in the form of $\mathrm{I}_{\mathrm{r}}\left(\mathrm{ds}_{n}\right)$. In the case of $\mathrm{ds}_{\mathbf{1}}$, the abundance ratio $I_{r}\left(\mathrm{ds}_{1}\right)$ increased dramatically as the molar ratio of the polyamide to duplex increased. The value of $\mathrm{I}_{\mathrm{r}}\left(\mathrm{ds}_{1}\right)$ was found to be 0.22 for the molar ratio of
$1: 1$, while the value was increased considerably, to 92 , as the mixing molar ratio was changed to 1:6. However, all $\mathrm{I}_{\mathrm{r}}\left(\mathrm{ds}_{n}\right)$ values of $\mathbf{d s}_{\mathbf{2}}$ to $\mathbf{d s}_{5}$ are less than 4 , at a mixing molar ratio of 1:1 nearly a 5-fold decrease in the $\mathrm{I}_{\mathrm{r}}\left(\mathrm{ds}_{n}\right)$ values could be approximated for $\mathbf{d s}_{2}$ to $\mathbf{d s}_{5}$, and when the mixing molar ratio was increased to $1: 6$, the results showed a more than 20-fold decrease in the value of $\mathrm{I}_{\mathrm{r}}\left(\mathrm{ds}_{n}\right)$ compared with that of $\mathbf{d s}_{\mathbf{1}}$. The $\mathrm{I}_{\mathrm{r}}\left(\mathrm{ds}_{n}\right)$ values of $\mathbf{d s}_{\mathbf{6}}$ and $\mathbf{d s}_{\mathbf{7}}$ are less than 1 for molar ratios from 1:1 to 1:6. These results show that the change of $\mathrm{I}_{\mathrm{r}}\left(\mathrm{ds}_{n}\right)$ values for $\mathbf{P}$ binding to the target DNA, $\mathbf{d s}_{\mathbf{1}}$ to $\mathrm{ds}_{7}$, is remarkable for discrimination of two to six base pairs difference between the DNA sequences.

The relative binding affinity $\left[\Delta \mathrm{I}_{\mathrm{r}}\left(\mathrm{ds}_{n}\right)\right]$ is defined in eq 2 and the $\Delta \mathrm{I}_{\mathrm{r}}\left(\mathrm{ds}_{1}\right)$ value of $\mathbf{d s}_{1}$ was defined to be $100 \%$ as the reference. In Figure 3, histograms of the ratio $\Delta \mathrm{I}_{\mathrm{r}}\left(\mathrm{ds}_{n}\right)$ summarize the relative binding affinity of the probe $\mathbf{P}$ to the target DNA for each titration point. Compared with $100 \%$ for $\mathbf{d s}_{\mathbf{1}}$ with the mixing molar ratio of 1:1 (Figure 3a), the $\Delta \mathrm{I}_{\mathrm{r}}\left(\mathrm{ds}_{n}\right)$ values for targets $\mathbf{d s}_{\mathbf{2}}$ to $\mathrm{ds}_{\mathbf{7}}$ were $21,16,27,23$, 12 , and $7 \%$, respectively, which revealed a substantial decrease in the overall signal intensity for the sequences that are not a perfect match with the polyamide $\mathbf{P}$. Similarly, the $\Delta \mathrm{I}_{\mathrm{r}}\left(\mathrm{ds}_{n}\right)$ values of the 1:6 mixing ratio for $\mathbf{d s}_{2}$ to $\mathrm{ds}_{7}$ were decreased to $4.9,3.4,5.6,2.7,0.5$, and $0.2 \%$, respectively (Figure $3 \mathrm{~d}$ ). Figure 3 shows that, when the concentration of $\mathbf{P}$ was increased, the difference of the relative affinity became greater between $\mathrm{ds}_{\mathbf{1}}$ and other 

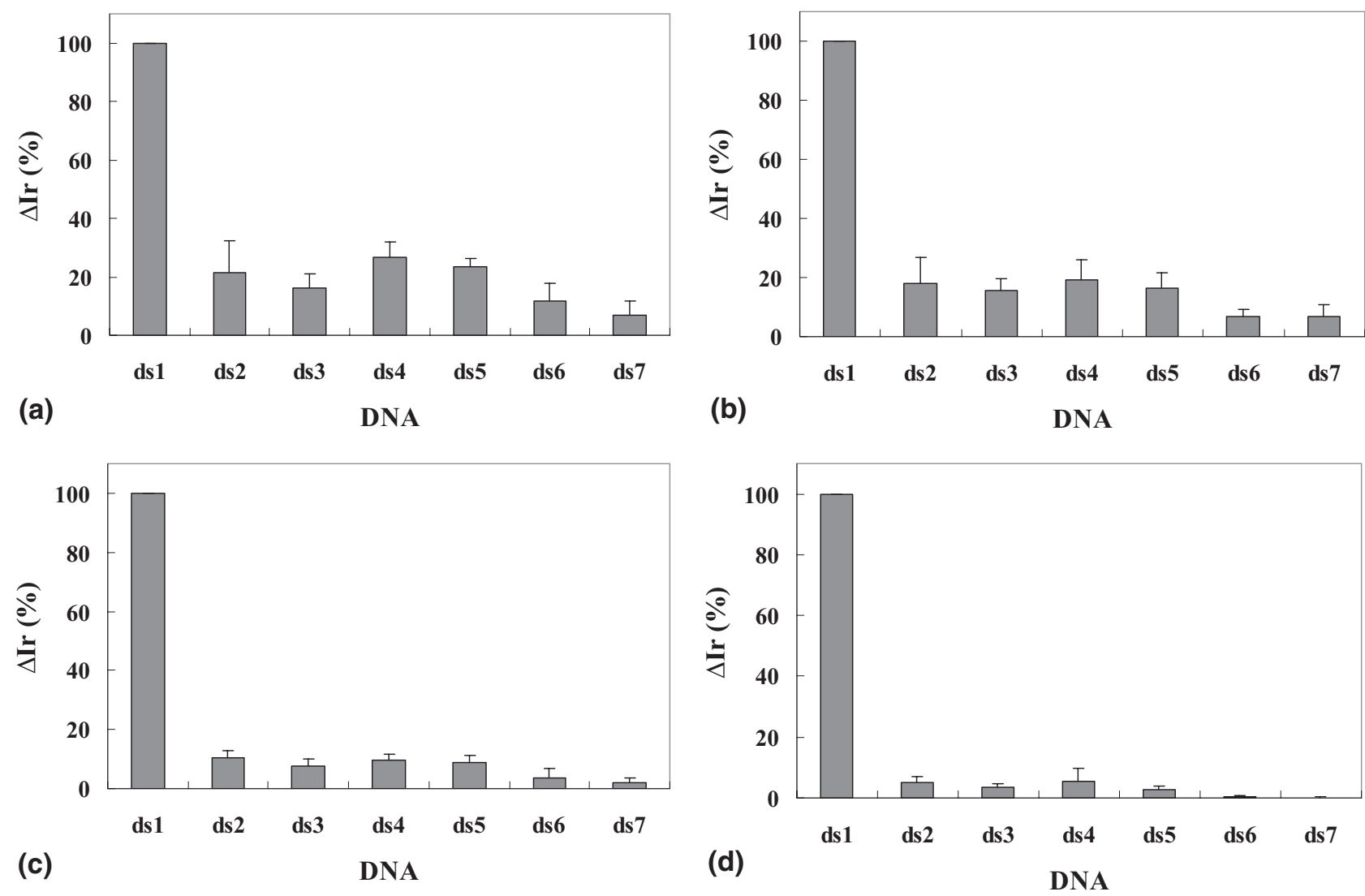

Figure 3. The relative binding affinities $\left[\Delta \mathrm{I}_{\mathrm{r}}\left(\mathrm{ds}_{n}\right)\right]$ of $\mathbf{d} \mathbf{s}_{n}(n=1-7)$ with $\mathbf{P}$, in the molar ratio of (a) 1:1; (b) $1: 2 ;\left(\right.$ c) $1: 4 ;(d) 1: 6\left(\Delta \mathrm{I}_{\mathrm{r}}\left(\mathrm{ds}_{\mathrm{n}}\right)\right.$ are average values of three measurements).

changed sequences, $\mathbf{d s}_{n}(n=2-7)$. It is because the perfectly matched sequence $\mathbf{d s}_{\mathbf{1}}$ could be bound more efficiently by the probe $\mathbf{P}$ that the abundance of the complex ion increased considerably, compared with other DNA sequences.

These results demonstrated the selectivity of $\mathbf{P}$ for $\mathbf{d s}_{1}$, and the probe $\mathbf{P}$ displays a discrimination function between the different A.T-rich sequences. The $\Delta \mathrm{I}_{\mathrm{r}}\left(\mathrm{ds}_{n}\right)$ values show that a clear difference existed between $\mathbf{~ d s}_{\mathbf{1}}-\mathbf{P}$ and $\mathbf{d s}_{n}-\mathrm{P}(n=2-7)$ interactions, indicating that ESI-MS can be used to detect sequence-dependent affinity; namely, to determine the relative binding affinities of $\mathbf{P}$ with the A.T-rich recognition sequence of DNA in the minor groove.

\section{Binding Selectivity of $P$ to SBPD DNA}

This method has been used to validate the sequencedependent affinity of $\mathbf{P}$ to target DNA with 2-6 base pairs difference in the ATATAA element. Here, our goal is to evaluate the utility of ESI-MS for analysis of binding selectivity of $\mathbf{P}$ to SBPD DNA. For this purpose, the single base pair substitution of G.C for A.T within the ATATAA element of the HIV-1 promoter was chosen as the mutation model. The corresponding sequences were introduced as $\mathrm{ds}_{\mathbf{1 1}}$ to $\mathbf{d s}_{\mathbf{1 6}}$, each of which has only one base pair difference from the natural DNA sequence, $\mathrm{ds}_{\mathbf{1}}$.

The ESI mass spectra of the noncovalent interaction

Table 2. The values of $\Delta \operatorname{Ir}\left(\mathrm{ds}_{n}\right)$ for different molar ratio $(n=1,11-16)^{*}$

\begin{tabular}{lllll}
\hline DNA & \multicolumn{1}{c}{$1: 1$} & $1: 2$ & $1: 4$ & $1: 6$ \\
\hline \hline $\mathrm{ds}_{1}$ & 100.0 & 100.0 & 100.0 & 100.0 \\
$\mathrm{ds}_{11}$ & $69.4 \pm 4.0$ & $45.8 \pm 12.2$ & $26.8 \pm 8.7$ & $34.9 \pm 6.9$ \\
$\mathrm{ds}_{12}$ & $46.1 \pm 14.5$ & $56.5 \pm 2.0$ & $30.4 \pm 8.8$ & $29.6 \pm 9.9$ \\
$\mathrm{ds}_{13}$ & $75.9 \pm 8.6$ & $71.2 \pm 9.8$ & $40.5 \pm 8.6$ & $33.6 \pm 7.8$ \\
$\mathrm{ds}_{14}$ & $48.0 \pm 17.0$ & $40.9 \pm 4.0$ & $29.0 \pm 7.0$ & $26.9 \pm 6.0$ \\
$\mathrm{ds}_{15}$ & $35.8 \pm 11.9$ & $53.9 \pm 13.4$ & $50.0 \pm 11.5$ & $34.3 \pm 17.3$ \\
$\mathrm{ds}_{16}$ & $42.6 \pm 1.7$ & $68.0 \pm 5.8$ & $35.8 \pm 7.0$ & $29.7 \pm 11.2$ \\
\hline
\end{tabular}

${ }^{*} \mathrm{ds}_{n}$ with P in molar ratio of 1:1, 1:2, 1:4, 1:6; Value is the average of three measurements. 
Table 3. Binding constants $\left(K_{\mathrm{a}}\right)$ of $\mathbf{P}$ with $\mathrm{ds}_{n}(n=1-7,11-16)$ by fluorescence analysis

\begin{tabular}{llll}
\hline DNA & $K_{\mathrm{a}}\left[\mathrm{M}^{-1}\right]$ & DNA & $K_{\mathrm{a}}\left[\mathrm{M}^{-1}\right]$ \\
\hline \hline $\mathrm{ds}_{1}$ & $9.3 \times 10^{6}$ & $\mathrm{ds}_{11}$ & $4.1 \times 10^{6}$ \\
$\mathrm{ds}_{2}$ & $1.5 \times 10^{6}$ & $\mathrm{ds}_{12}$ & $3.7 \times 10^{6}$ \\
$\mathrm{ds}_{3}$ & $1.4 \times 10^{6}$ & $\mathrm{ds}_{13}$ & $4.0 \times 10^{6}$ \\
$\mathrm{ds}_{4}$ & $1.0 \times 10^{6}$ & $\mathrm{ds}_{14}$ & $4.3 \times 10^{6}$ \\
$\mathrm{ds}_{5}$ & $1.3 \times 10^{6}$ & $\mathrm{ds}_{15}$ & $4.0 \times 10^{6}$ \\
$\mathrm{ds}_{6}$ & $4.4 \times 10^{5}$ & $\mathrm{ds}_{16}$ & $4.3 \times 10^{6}$ \\
$\mathrm{ds}_{7}$ & $3.7 \times 10^{5}$ & & \\
\hline
\end{tabular}

were analyzed by mixing $\mathbf{d s}_{\mathbf{1 1}}$ to $\mathbf{d s}_{\mathbf{1 6}}$ with $\mathbf{P}$ in different molar ratios, respectively. Here, the typical ESI mass spectra of mixtures of $\mathbf{d s}_{n}(n=11-16)$ with $\mathbf{P}$ in a $1: 4 \mathrm{M}$ ratio are described as examples. The spectra contain three main peaks of $m / z 1704.3\left(\left[\mathrm{ds}_{n}\right]^{5-}\right), 1833.6\left(\left[\mathrm{ds}_{n}+\right.\right.$ $\left.\mathrm{P}]^{5-}\right)$, and $1963.1\left(\left[\mathrm{ds}_{n}+2 \mathrm{P}\right]^{5-}\right)$. The relative abundances of $\left[\mathrm{ds}_{n}+2 \mathrm{P}\right]^{5-}$ ions are all $100 \%$ for $\mathbf{d s}_{11}$ to $\mathrm{ds}_{\mathbf{1 6}}$. The abundances of $\left[\mathrm{ds}_{n}+\mathrm{P}\right]^{5-}$ are $6,7,4,26,8$, and $6 \%$, and that of $\left[\mathrm{ds}_{n}\right]^{5-}$ are $21,26,32,14,28$, and $22 \%$ for $\mathbf{d s}_{11}$ to $\mathbf{d s}_{16}$, respectively. Using the method mentioned above, the relative abundances of $\left[\mathrm{ds}_{n}+2 \mathrm{P}\right]^{5-}$ and $\left[\mathrm{ds}_{n}\right]^{5-}$ in the ESI-MS spectra of the titration experiments of $\mathbf{P}$ binding with variants of duplex DNA $\mathbf{d s}_{\mathbf{1 1}}$ to $\mathrm{ds}_{\mathbf{1 6}}$ were monitored with increasing the concentration of $\mathbf{P}$.

$\mathrm{I}_{\mathrm{r}}\left(\mathrm{ds}_{n}\right)$ and corresponding $\Delta \mathrm{I}_{\mathrm{r}}\left(\mathrm{ds}_{n}\right)$ values were obtained at different molar ratios (1:1, 1:2, 1:4 and 1:6) using eqs 1 and 2 , and the mean values were calculated from ESI mass spectra of three measurements. Table 2 shows that there are only some decreases in the $\Delta \mathrm{I}_{\mathrm{r}}\left(\mathrm{ds}_{n}\right)$ values for $\mathrm{ds}_{\mathbf{1 1}}$ to $\mathrm{ds}_{\mathbf{1 6}}$ in the molar ratio of 1:1, compared with that of $\mathbf{d s}_{\mathbf{1}}$. This may be attributed to the weak signal intensities of the complex ions when the concentration of $\mathbf{P}$ is only $25 \mu \mathrm{M}$ at the first titration point. In this case, the background noise in the ESI mass spectra would have considerable influence on the signal intensity. However, with the concentration of $\mathbf{P}$ increased, 1:2 complex ions $\left(\left[\mathrm{ds}_{n}+2 \mathrm{P}\right]^{5-}\right)$ became significant with greater abundance. As shown in Table 2, the ratio contrast between $\mathbf{d s}_{\mathbf{1}}-\mathbf{P}$ and $\mathbf{d s}_{n}-\mathrm{P}(n=11-16)$ could be clearly observed with the mixing molar ratio changing from $1: 2$ to $1: 6$. For the reliability of the experimental results, the measurements with the mixing molar ratio of 1:4 and 1:6 are more suitable for evaluation of the binding selectivity of the polyamide to singlebase pair different DNA. The relative binding affinities $\left[\Delta \mathrm{I}_{\mathrm{r}}\left(\mathrm{ds}_{n}\right)\right]$ are decreased remarkably for the interaction of $\mathbf{d s}_{\mathbf{1 1}}$ to $\mathbf{d s}_{\mathbf{1 6}}$ with the probe $\mathbf{P}$, these values were less than half $(50 \%)$ of that for the natural sequence $\mathrm{ds}_{\mathbf{1}}(100 \%)$, and with better reproducibility in most cases. These results show that $\mathbf{P}$ has a high selectivity for $\mathbf{d s}_{\mathbf{1}}$, and relative binding affinities, $\Delta \mathrm{I}_{\mathrm{r}}\left(\mathrm{ds}_{n}\right)$, could be used for the evaluation of binding selectivity of $\mathbf{P}$ to SBPD DNA in the A.T-rich region.

\section{Fluorescence Titration}

A fluorescence titration assay was used to compare and confirm the ESI-MS results. Since the fluorescence of both DNA and the polyamide is too weak to be measured directly, a fluorescent intercalator displacement (FID) assay, based on the displacement of ethidium bromide, was chosen instead of direct titration [34, 35]. Using eqs 3-6, a Scatchard plot was generated where $\Delta \mathrm{F} /[$ Free $\mathrm{P}]$ was plotted versus $\Delta \mathrm{F}$, the slope of the linear portion provided a measure of the binding constant $K_{\mathrm{a}}[34]$.

$$
\begin{aligned}
& \left(\Delta \mathrm{F} / \Delta \mathrm{F}_{\text {sat }}\right)(1 / \mathrm{X})=\text { Fraction of }\left(\mathbf{d s}_{n}+\mathbf{P}\right) \text { complex } \\
& 1-\left(\Delta \mathrm{F} / \Delta \mathrm{F}_{\text {sat }}\right)(1 / \mathrm{X})=\text { Fraction of free } \mathbf{P} \\
& {[\text { DNA }]_{\mathrm{T}}\left[\mathrm{X}-\left(\Delta \mathrm{F} / \Delta \mathrm{F}_{\text {sat }}\right)\right]=[\text { Free } \mathbf{P}]} \\
& K_{a}=- \text { slope }
\end{aligned}
$$

where [free $\mathrm{P}$ ] is the concentration of free polyamide, $[D N A]_{T}$ is the total concentration of DNA, $X$ is the molar ratio of polyamide versus DNA, $\Delta \mathrm{F}$ is the change in fluorescence, and $\Delta \mathrm{F}_{\text {sat }}$ is the change in fluorescence at the point where DNA is saturated with the ligand.

The results of the FID assays given in Table 3 are in good agreement with those obtained by ESI-MS. There are prominent decreases in the $K_{\mathrm{a}}$ values for the two to six base pair different DNAs $\left(\mathbf{d s}_{\mathbf{2}}\right.$ to $\left.\mathbf{d s}_{\mathbf{7}}\right)$, compared with that of $\mathbf{d s}_{\mathbf{1}}$. For SBPD DNA, the $K_{\mathrm{a}}$ values of $\mathbf{d s}_{11}$ to $\mathbf{d s}_{16}\left(\sim 4.3 \times 10^{6} \mathrm{M}^{-1}\right)$ for interaction with $\mathbf{P}$ were less than half of that for $\mathbf{d s}_{\mathbf{1}}\left(9.3 \times 10^{6} \mathrm{M}^{-1}\right)$; and the binding affinity order of $\mathbf{P}$ to $\mathbf{d s}_{n}(n=1-7,11-16)$ is almost the same as that obtained by ESI-MS.

However, the FID assay is often labor-intensive and may require large quantities of DNA. The advantages of ESI-MS for binding affinity studies include the speed of analysis and the ability to obtain stoichiometric information.

\section{Conclusions}

This study has succeeded in the development of an ESI-MS method for the evaluation of the binding selectivity of a polyamide to SBPD DNA. The analysis procedure can be accomplished within a few minutes because of the speed of mass spectrometry and the efficient selective recognition of the polyamide. This ESI-MS method should be applicable to rapid analysis of the binding selectivity of a polyamide probe to an SBPD DNA in gene fragments for the exploration of biological phenomena, and developing the potential of polyamide applications in the life sciences. Additional information, discussing the description of the ESI mass spectra of the mixtures of dsn with $\mathrm{P}$ in 1:2 molar ratio $(\mathrm{n}=1-7,11-16)$ and the fluorescence titration assays of the polyamide probe $\mathrm{P}$ versus ds1 and ds11, is available in the Supplementary Material section, which can be found in the electronic version of the article. 


\section{Acknowledgments}

This project was supported by the National Natural Science Foundation of China (no. 20272005, 20472009) and the Research Fund for the Doctoral Program of Higher Education.

\section{References}

1. Morrison, H. L.; Soni, B.; Lenz, J. Long Terminal Repeat Enhancer Core Sequences in Proviruses Adjacent to c-myc in T-Cell Lymphomas Induced by a Murine Retrovirus. I. Virol. 1995, 69, 446-455.

2. Kovacikova, G.; Skorupski, K. Differential Activation of the tcpPH Promoter by AphB Determines Biotype Specificity of Virulence Gene Expression in Vibrio cholerae. J. Bacteriol. 2000, 182, 3228-3238.

3. Cantwell, C. A.; Sterneck, E.; Johnson, P. F. Interleukin-6-Specific Activation of the C/EBP $\delta$ gene in Hepatocytes is Mediated by Stat 3 and Sp1. Mol. Cell. Biol. 1998, 18, 2108-2117.

4. Geierstanger, B. H.; Mrksich, M.; Dervan, P. B.; Wemmer, D. E. Design of a GC-Specific DNA Minor Groove-Binding Peptide. Science 1994, 266, $646-650$.

5. Trauger, J. W.; Baird, E. E.; Dervan, P. B. Recognition of DNA by Designed Ligands at Subnanomolar Concentrations. Nature 1996, 382, 559-561.

6. Gottesfeld, J. M.; Neely, L.; Trauger, J. W.; Baird, E. E.; Dervan, P. B. Regulation of Gene Expression by Small Molecules. Nature 1997, 387, 202-205.

7. White, S.; Szewczyk, J. W.; Turner, J. M.; Baird, E. E.; Dervan, P. B. Recognition of the Four Watson-Crick Base Pairs in the DNA Minor Groove by Synthetic Ligands. Nature 1998, 391, 468-471.

8. Clarke, M. J.; Sadler, P. J., Eds.; Metallopharmaceuticals I: DNA Interactions, Topics in Biological Inorganic Chemistry; Vol. I. Springer-Verlag. Berlin, 1999.

9. Propst, C. L.; Perun, T. J. Nucleic Acid Targeted Drug Design; Marcel Dekker, Inc.; New York, 1992, pp 303-374.

10. Fricker, S. P. Metal Compounds in Cancer Therapy; Chapman and Hall: London, UK, 1994, pp 32-146.

11. Erkkila, K. E.; Odom, D. T.; Barton, J. K. Recognition and Reaction of Metallointercalators with DNA. Chem. Rev. 1999, 99, 2777-2796.

12. Reedijk, J. DNA-Binding Properties of Heavy-Metal Complexes and Consequences of Structural Changes. Macromol. Symp. 2000, 156, 277284.

13. Reddy, B. S. P.; Sondhi, S. M.; Lown, J. W. Synthetic DNA Minor Groove-Binding Drugs. Pharmacol. Ther. 1999, 84, 1-111.

14. Gambari, R.; Beriotto, G.; Rutidliano, C.; Bianchi, N.; Mischiati, C. Biospecific Interaction Analysis of Low-Molecular Weight Binding Drugs. J. Pharmacol. Exp. Ther. 2000, 294, 370-377.

15. Weyermann, P.; Dervan, P. B. Recognition of Ten Base Pairs of DNA by Head-to-Head Hairpin Dimers. J. Am. Chem. Soc. 2002, 124, 6872-6878.

16. Melander, C.; Herman, D. M.; Dervan, P. B.Discrimination of A/T Sequences in the Minor Groove of DNA Within a Cyclic Polyamide Motif. Chem. Eur. J. 2000, 6, 4487-4497.

17. Fechter, E. J.; Olenyuk, B.; Dervan, P. B. Sequence-Specific Fluorescence Detection of DNA by Polyamide-Thiazole Orange Conjugates. J. Am. Chem. Soc. 2005, 127, 16685-16691.
18. Dervan, P. B.; Edelson, B. S. Recognition of the DNA Minor Groove by Pyrrole-Imidazole Polyamides. Curr. Opin. Stuct. Biol. 2003, 13, 283-299.

19. Gale, D. C.; Goodlett, D. R.; Light-Wahl, K. J.; Smith, R. D. Observation of Duplex DNA-Drug Noncovalent Complexes by Electrospray Ionization Mass Spectrometry. J. Am. Chem. Soc. 1994, 116, 6027-6028.

20. Gabelica, V.; Pauw, E. D.; Rosu, F. Interaction Between Antitumor Drugs and a Double-Stranded Oligonucleotide Studied by Electrospray Ionization Mass Spectrometry. J. Mass. Spectrom. 1999, 34, 1328-1337.

21. Wan, K. X.; Shibue, T.; Gross, M. L. Noncovalent Complexes Between DNA-Binding Drugs and Double-Stranded Oligodeoxynucleotides: A Study by ESI Ion-Trap Mass Spectrometry. J. Am. Chem. Soc. 2000, 122, 300-307.

22. Reyzer, M. L.; Brodbelt, J. S.; Kerwin, S. M.; Kumar, D. Evaluation of Complexation of Metal-Mediated DNA-Binding Drugs to Oligonucleotides Via Electrospray Ionization Mass Spectrometry. Nucleic Acids Res. 2001, 29, e103.

23. David, W. M.; Brodbelt, J.; Kerwin, S. M.; Thomas, P. W. Investigation of Quadruplex Oligonucleotide-Drug Interactions by Electrospray Ionization Mass Spectrometry. Anal. Chem. 2002, 74, 2029-2033.

24. Rosu, F.; Gabelica, V.; Houssier, C.; Pauw, E. D. Determination of Affinity, Stoichiometry and Sequence Selectivity of Minor Groove Binder Complexes with Double-Stranded Oligodeoxynucleotides by Electrospray Ionization Mass Spectrometry. Nucleic Acids Res. 2002, 30, e82.

25. Rosu, F.; Gabelica, V.; Shin, K. Y.; Pauw, E. D. Telomestatin-Induced Stabilization of the Human Telomeric DNA Quadruplex Monitored by Electrospray Mass Spectrometry. Chem. Commun. 2003, 3, 2072-2073.

26. Zhou, J.; Yuan, G.Analysis of Noncovalent Complexes Between Human Telomeric DNA and Polyamides Containing N-Methylpyrrole and N-Methylimidazole by Using Electrospray Ionization Mass Spectrometry. Chem. Eur. J. 2005, 11, 1157-1162.

27. Tutter, A.; Jones, K. A. Chemicals that Footprint DNA: Hitting HIV-1 in the Minor Groove Proc. Natl. Acad. Sci. US. A 1998, 95, 12739-12741.

28. Dickinson, L. A.; Gulizia, R. J.; Trauger, J. W.; Baird, E. E.; Mosier, D. E.; Gottesfeld, J. M.; Dervan, P. B. Inhibition of RNA Polymerase II Transcription in Human Cells by Synthetic DNA-Binding Ligands. Proc. Natl. Acad. Sci. U.S.A. 1998, 95, 12890-12895.

29. Wemmer, D. E.; Dervan, P. B. Targeting the Minor Groove of DNA. Curr. Opin. Struct. Biol. 1997, 7, 355-361.

30. Jones, K. A.; Peterlin, B. M. Control of RNA Initiation and Elongation at the HIV-1 Promoter. Annu. Rev. Biochem. 1994, 63, 717-743.

31. Dervan, P. B. Molecular Recognition of DNA by Small Molecules. Bioorg. Med. Chem. 2001, 9, 2215-2235.

32. Yuan, G.; Tang, F. L. Synthesis of DNA-Recognizing Polyamides Containing N-Methylpyrrole and N-Methylimidazole. Arkivoc 2003, Part 2, 32-37.

33. Xiao, J. H.; Yuan, G.; Huang, W. Q.; Chan, A. S. C.; Lee, K. L. D. A Convenient Method for the Synthesis of DNA-Recognizing Polyamides in Solution. J. Org. Chem. 2000, 65, 5506-5513.

34. Boger, D. L.; Fink, B. E.; Brunette, S. R.; Tse, W. C.; Hedrick, M. P. A Simple, High-Resolution Method for Establishing DNA Binding Affinity and Sequence Selectivity. I. Am. Chem. Soc. 2001, 123, 5878-5891.

35. Tse, W. C.; Boger, D. L. A Fluorescent Intercalator Displacement Assay for Establishing DNA Binding Selectivity and Affinity. Acc. Chem. Res. 2004, 37, 61-69. 